\title{
Monitoring of water extent and variation of the Poyang Lake using GF-1 remote sensing data Yu Zhou ${ }^{1,2, a}$, Li Zhang ${ }^{1,2, b}$ and Yeqiao Wang ${ }^{1,2, c}$ \\ ${ }^{1}$ Key Laboratory of Poyang Lake Wetland and Watershed Research, Ministry of Education, Jiangxi Normal University, China; \\ ${ }^{2}$ School of Geography and Environment, Jiangxi Normal University, China; \\ akingkillgl@sina.com, bhanglinu@126.com, cywang0559@126.com
}

Keywords: GF-1, Poyang Lake, NDWI, Water extent variation

Abstract. Based on the 76 scenes of GF-1 WFV images in Jun 2013 Jun 2016. After processing, a total of 22 times of Poyang Lake area images. Water extents of Poyang Lake area were extracted by Normalized Difference Water Index (NDWI) and analyzed for water surface variation in time sequence. The results show periodic water extent variation of Poyang Lake. Water area begins to rise faster from April to June, and reaches peak in July and August. Water area gradually declines in September, until January of the following year and reaches the minimum. Poyang Lake annually has its own unique change characteristics. In December 16, 2015, Poyang Lake had abnormal high water level and water area was $2349.31 \mathrm{~km}^{2}$. The variation shows that the main water area and the dish-shaped sublakes surrounding of Poyang Lake change little, and the change of water area in Poyang Lake wetland is obvious.

\section{Introduction}

Satellite remote sensing is a kind of space technology which can obtain the large area and high frequency of surface information, it has been widely used in water resources investigation, flood monitoring, and land use. By multi-temporal satellite images, variation information of lake surface can be obtained. The lake in highly dynamic water level changing, which needs real-time, dynamic and cyclical characteristics of remote sensing.

At present, many domestic and foreign scholars choose multi-temporal Landsat [1] satellite images as data sources to monitor the lake surface information. MODIS [2], SPOT and SAR images are also widely applied in water extent monitoring. The international satellites mainly are selected to monitor water extent in Chinese lakes. Despite the domestic satellites have the rapid development, such as HJ, CBERS, they are lack of application. Currently, China's self-developed high-satellite on the dynamic monitoring of lake water information needs further exploration.

GF-1 satellite was successfully launched on April 26, 2013.GF-1 is the first satellite in the national high resolution earth observation system [3]. Compared with Landsat TM, MDIS and SPOT images, GF-1 images integrate high temporal and spatial resolution. GF-1 plays an important role for the monitoring of atmospheric environment, water and eco-environment in China. Therefore, according to the high dynamic changing of water level and water extent of Poyang Lake, using the high spatial resolution, high time resolution and wide swath coverage characteristics of GF- 1 . The 76 scenes of GF-1 WFV images collected from Jun 2013 -Jun 2016 were processed. After geometric correction and mosaic, a total of 22 times of remote sensing images were prepared to cover the Poyang Lake area. Water extents of Poyang Lake area were extracted by normalized difference water index (NDWI) and analyzed for water surface variation in time sequence. The results provide the reference data and technical support for Poyang Lake water resources investigation and assessment, flood prevention, wetlands and migratory bird habitat and ecological security assessment.

\section{Study area and data}

Study area. Poyang Lake is located in the north of Jiangxi Province, the south of the middle reaches of the Yangtze River, it is also the largest freshwater lake in China. Poyang Lake collect Ganjiang 
River, Fu River, Xinjiang, Rao River, Xiu River, after flowing, water of Poyang Lake finally import to the Yangtze River. The water extent of Poyang Lake affected by Yangtze River backwater, with dramatic and seasonal characteristics. Poyang Lake in wet season in April September, the dry season is from October to March of the following year.

Based on the maximum water area coverage of Poyang Lake as a study area, extracting and analyzing water extent of the boundaries of the largest water area, using the timeliness and spatial coverage advantage of remote sensing data to monitor the change of water area.

Data. GF-1 is equipped with $2 \mathrm{~m}$ resolution panchromatic camera, $8 \mathrm{~m}$ resolution multispectral camera and $16 \mathrm{~m}$ resolution multi-spectral cameras. GF-1 data has high spatial resolution and high temporal resolution and wide swath coverage. $16 \mathrm{~m}$ resolution multi-spectral cameras have more than $800 \mathrm{~km}$ image width and revisit period for 4 days.

This study is based on $16 \mathrm{~m}$ spatial resolution WFV images of GF-1. WFV images include blue (Band1, 0.45 0.52 $\mu \mathrm{m}$ ), green (Band2, 0.52 0.59 $\mu \mathrm{m}$ ), red (Band3, 0.63 0.69 $\mu \mathrm{m}$ ), near infrared (Band4, 0.77 0.89 $\mu \mathrm{m}$ ). Images select images from the same month in the 2013 to 2016, a total of 76 scenes, including April, June and August in wet season, as well as October, December, January and March in dry season.GF-1 WFV image preprocessing based on ENVI5.1 software platform. The final study data has been through radiometric calibration, FLAASH atmospheric correction, geometric correction and image cut. The precision of results is controlled in one pixel.

\section{Method}

Boundary. In this paper, using the flooding area of the highest water level in wet season of Poyang Lake as reference. Selecting July 8, 1998 Landsat-5 TM image to extract boundary of study area. Study area includes the main water area, transition water and the dish-shaped sublakes surrounding of Poyang Lake wetlands.

Extraction. Water in the visible range, the reflectivity is lower, generally 4\% 5\%, and decreases with the increasing of wavelength [4]. The highest reflectance in the blue and green bands, the lowest in the near infrared band, and the characteristics of water reflectivity are the foundation of water extraction. The band of GF-1 WFV image can correspond to the band of Landsat TM image. The method of TM image extraction can be used for GF-1 image.

Water extraction methods include Single-band threshold method [5], Multiple-band method [6], Support Vector Machine method [7] and NDWI (Eq. 1) method [8].

$$
\mathrm{NDWI}=\left(\mathrm{B}_{2}-\mathrm{B}_{4}\right) /\left(\mathrm{B}_{2}+\mathrm{B}_{4}\right) .
$$

After precision [9] analysis, the result is shown in Tab.1, this paper uses NDWI to extract water from GF-1 WFV data. According to the experiments, water can be extracted by -0.15 of NDWI during dry season, the threshold of wet season is 0 , and the threshold of the other time is 1 .

Tab. 1 the precision contrast based on different water extraction

\begin{tabular}{lcccc}
\hline Method & Single-band & Multiple-band & SVM & NDWI \\
\hline Precision[\%] & 88.3 & 92.8 & 94.5 & 96.4 \\
Kappa & 0.77 & 0.82 & 0.84 & 0.87 \\
\hline
\end{tabular}

\section{Results}

Change trend. The water level of Poyang Lake has seasonal variation. The water extent changing curve of Poyang Lake is shown in Fig 1. The results show the water area began to rise faster from April to June, and reached peak in July and August. Water area gradually declined in September, until January of the following year and reached the minimum. From June 2013 to June 2016, the largest water area of Poyang Lake was $3317.55 \mathrm{~km}^{2}$ in June 5,2016 . The water area was the smallest in January 22, 2014, as the water area was $987.58 \mathrm{~km}^{2}$. The largest water area was 3.6 times larger than the minimum area. The result shows the change trend of water area of Poyang Lake is basically same in different years, but each year has unique characteristics of Variation. 
Variation. Based on 22 times of GF-1 WFV images, and obtained the extent variation of Poyang Lake by spatial analysis, result is shown in Fig 2. The study found that the main water and channel of Poyang Lake, closed lakes and dish-shaped sublakes surrounding of Poyang Lake had changed small, those areas were covered with water in long time and were $29 \%$ of the study area. Transition zone showed the dramatic variation between the wet season and dry season in Poyang Lake, and represented the variation range of Poyang Lake wetland, accounting for 55\% of the study area. For example, in Nan Jishan National Wetland Reserve, the dish-shaped sublakes had few changes. Other study area were mountains, hills and villages surrounded by Poyang Lake, which hardly flooded by lake water, and accounted for $16 \%$ of all area.
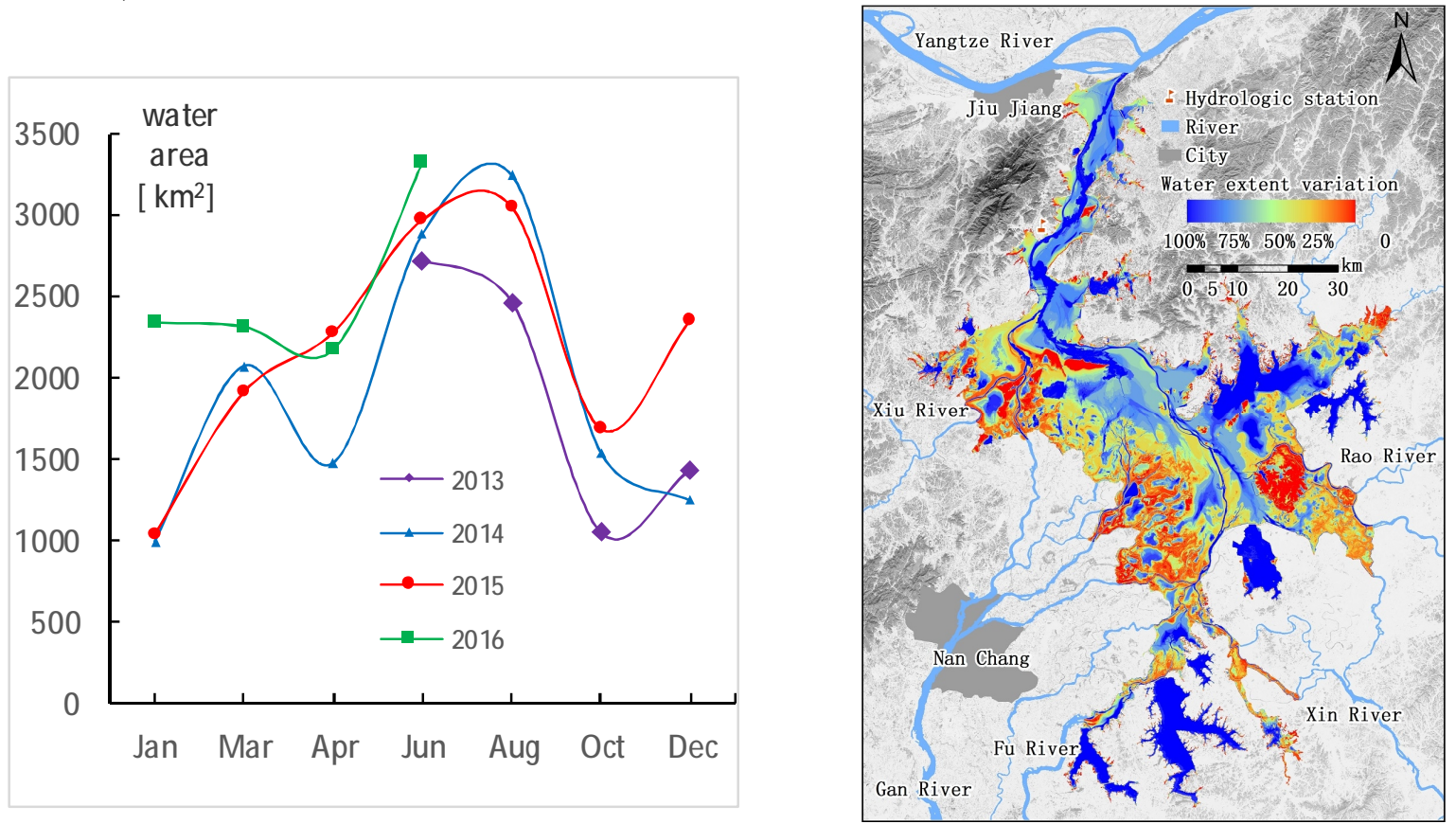

Fig.1 The water extent changing curve of Poyang Lake Fig.2 Water extent variation of Poyang Lake

Comparison. Water extent comparison of Poyang Lake in dry season in 2013, 2014 and 2015 is shown in the Fig 3. The water area of Poyang Lake was $2349.31 \mathrm{~km}^{2}$ in December 16, 2015, which was 1.9 times of same period in 2014, and 1.6 times of 2013. In December 21, 2013, as the water area was $1429.34 \mathrm{~km}^{2}$, in December 24, 2014, as the water area was $1237.46 \mathrm{~km}^{2}$. During the dry season in December 2015, water area of Poyang Lake close to the wet season of the same year, on April 14, with the area was $2272.87 \mathrm{~km}^{2}$. Results show Poyang Lake had abnormal high water level and large water area during the dry season in winter 2015, it continued until next March of the following year. From 2015 to 2016, the lager water area of Poyang Lake in dry season had impact of Poyang Lake wetlands and migratory bird.

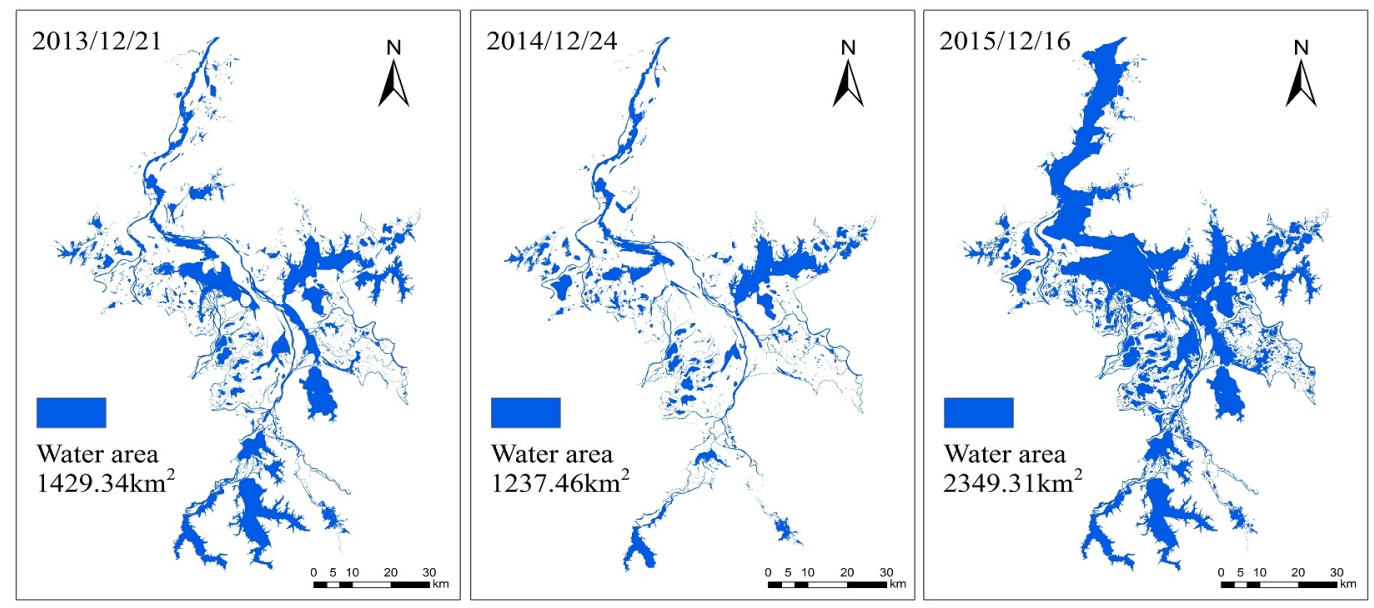

Fig.3 Water extent comparison of Poyang Lake in dry season 


\section{Conclusions}

Using NDWI to extract water from GF-1 WFV image data has high practicability for the open water body in the study area of Poyang Lake. The results show that the whole water area of Poyang Lake can be accurately monitored and analyzed by GF-1 WFV images, because GF-1 WFV data has high spatial resolution, high time resolution and wide swath coverage characteristics.GF-1 WFV images also can accurately show the details of water variation in dish-shaped sublakes. GF-1 provided effective basic data for monitoring and researching the water extent variation of Poyang Lake.

In this study, the water extent of Poyang Lake mainly had seasonal changes. During the wet season, the water area of Poyang Lake expanded significantly in April June, it continued to enlarged and appeared peak in July August with flood of Yangtze River. The water area started to decrease in September, it sharply declined in October. During the dry season, the water area were at minimum period, from December to next February. On June 5, 2016, water area of Poyang Lake was close to the maximum during the flood in 1998. On January 22, 2014, water area was close to the minimum in dry season in 2004. When overall changes of water area of Poyang Lake were mainly same, the annual water variation of Poyang Lake each had different characteristics. For example, From December 2015 to March 2016, Poyang Lake had abnormal high water level and large water area in dry season, the area was 1.9 times of same period in 2014, and 1.6 times of 2013.

From the results of water extent variation of Poyang Lake in 2013-2016, 29\% of the study area are covered water over a long period of time. The transition region occupied 55\%, which included main water area and wetlands. Transition zone reflected seasonal variation of Poyang Lake especially the range of wetland.

\section{Acknowledgements}

This work was financially supported by the National Natural Science Foundation of China (41471298), and Natural Science Foundation of Jiangxi (20133ACB20011).

\section{References}

[1] M.G. Tulbure, M. Broich, S.V. Stehman, and A. Kommareddy: Remote Sensing of Environment (2016).

[2] H. Yesou, C. Huber, and X.J. Lai: Lakes \& Reservoirs: Research and Management (2011).

[3] G.Z. Bai: Aerospace China (2013) In Chinese.

[4] X.A. Mei, W.L. Peng, and Q.M. Qin: Remote Sensing Introduction (Higher Education Press, China 2001) In Chinese.

[5] W. Wang, X. Zhu, and Y.C. Sun: Journal of System Simulation (2013) In Chinese.

[6] Q.F. Song, S.J. Wang, and Z. Zhang: Remote Sensing for Land and Resources (2011) In Chinese.

[7] Q.Y. Duan, L.K. Meng, and Z.W. Fan: Remote Sensing for Land and Resources (2015) In Chinese.

[8] S.K. Mcfeeters: International Journal of Remote Sensing (1996).

[9] W.Q. Chen, J.L. Ding, and Y.H. Li: Resources Science (2015) In Chinese. 